\title{
Uso de imágenes satélites para el estudio de los procesos de erosión en las marismas de Isla Cristina (Huelva)
}

\section{Use of satellite images to study erosion processes at Isla Cristina's salt-marshes}

DOI: $10.46932 / \mathrm{sfjdv2n3-076}$

Received in: May 1st, 2021

Accepted in: Jun 30th, 2021

\section{Emilio Ramírez-Juidías}

Departamento de Ingeniería Gráfica, Escuela Técnica Superior de Ingeniería Agronómica, Universidad de Sevilla, Carretera de Utrera km 1, 41013-Sevilla, España.

E-mail: erjuidias@us.es

\section{RESUMEN}

En este artículo, una nueva metodología fue utilizada para obtener el volumen total de suelo erosionado en las marismas de Isla Cristina. Del mismo modo, las diferentes causas que han dado lugar a este fenómeno, así como la influencia de los procesos inter-mareales son discutidas. Los resultados muestran cómo los procesos de erosión se encuentran relacionados no solo con los cambios de uso de suelo (CUS), sino también con la disminución relativa de indicadores de sostenibilidad espacial y temporal, piezas clave del aumento de erosión.

Palabras clave: imágenes satélite, suelo erosionado, NDVI, lógica difusa.

\section{ABSTRACT}

In this paper, a new methodology was used to obtain the total volume of eroded soil at Isla Cristina's saltmarshes. In the same way, the different causes that give rise to this phenomenon as well as the influence of intertidal processes are discussed. The results show how the erosion processes are in relationship not only with the land use changes (LUC), but also with the relative decrease in indicators of both spatial and temporal sustainability, key pieces of the increase in erosion.

Keywords: satellite imagery, eroded soil, NDVI, fuzzy logic.

\section{INTRODUCCIÓN}

Aunque los procesos naturales llevados a cabo en todo ecosistema, con sus implicaciones en lo que a los CUS se refiere, han sido estudiados en todo el mundo, es difícil extrapolar los resultados obtenidos a otras zonas, sobre todo a nivel de pequeña escala (Ramírez-Juidías et al., 2014). A pesar de que las plataformas aerotransportadas pueden contribuir a la solución de este problema, el uso de imágenes satélite de muy alta resolución (MAR) presenta una importante ventaja, ya que suministra la información espacial necesaria para el análisis a escala de marisma, además de aquella relevante de cara a la relación entre el cambio climático y la erosión de suelo.

Como es sabido, la erosión representa uno de los riesgos ambientales más importantes, llegando incluso a influir negativamente en la capacidad de soporte del medio natural. En las marismas de Isla 
Cristina, el sucesivo arrastre de sedimentos ocasiona cambios sustanciales en su forma física y su salud ecológica, dando lugar a un régimen de inundaciones variable relacionado con las mareas, la intervención humana, la interacción del viento y la influencia fluvial entre otros aspectos. Por otro lado, y tal y como especifica Soto et al. (2015), las condiciones endógenas de dichas marismas (levedad del relieve) contribuyen sinérgicamente en la geodinámica exógena del paisaje, siendo por sí mismas agentes generadores de procesos que derivan en condiciones de amenaza.

Hasta la fecha, la mayoría de estudios sobre teledetección en marismas han realizado, a partir de cambios espacio-temporales en la cubierta vegetal y/o la abundancia de especies existentes, aproximaciones en cuanto a la cuantificación de la pérdida de suelo se refiere, todas basadas en la reflectancia de los diferentes tipos de suelo y/o de dosel vegetal. Sin embargo, las nuevas técnicas de tratamiento digital de imágenes permiten el uso de metodologías basadas en lógica difusa, gracias a las cuales es posible obtener soluciones muy próximas a la realidad, sobre todo cuando interaccionan entre sí imágenes MAR y datos procedentes de UAV equipado con sensor radar de escaneo electrónico.

En el presente artículo, cuyo objetivo es predecir la erosión de suelo en las marismas de Isla Cristina, el análisis integrado de variables ambientales y topográficas permitirá identificar las áreas susceptibles de sufrir fenómenos de pérdida o acumulación de suelo, para lo cual el análisis de las inundaciones asociadas al drenaje del suelo, así como la uso de modelos digitales del terreno y obtención de modelos digitales de superficie (genéricamente ambos llamados modelos digitales de elevaciones (MDE)), será de vital importancia.

\section{MATERIAL Y MÉTODOS}

\section{1 ÁREA DE ESTUDIO}

De acuerdo con Ojeda-Zujar et al. (2006), el Paraje Natural Marismas de Isla Cristina (Figura 1), incluido en el estuario del río Guadiana, está constituido por una compleja red de drenaje dendrítica con canales, caños y esteros colmatados por sucesivos arrastres sedimentarios, que forman marismas mareales asociadas a la desembocadura de los ríos Guadiana y Carreras.

Con un área total de 2498.04 hectáreas, la vulnerabilidad del espacio según el riesgo de amenaza (REDIAM, 2008), se clasifica como muy alto en un $42 \%$ de su superficie, como alto en un $32 \%$, y como moderado en el $26 \%$ restante. 
Figura 1. Localización de la zona de estudio.

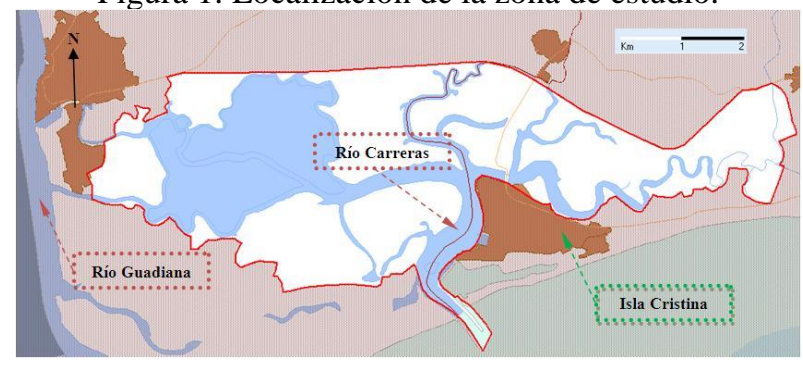

En otro orden de cosas, el clima de la zona puede ser definido como mediterráneo oceánico, con un grado de insolación que supera las 4200 horas/año. Durante la estación de invierno, destacada por un corto periodo de bajas temperaturas, es cuando se producen la mayor parte de las precipitaciones. Por otro lado, los veranos, secos y largos, son suaves debido a su proximidad al océano atlántico, no excediéndose la temperatura máxima absoluta de $43{ }^{\circ} \mathrm{C}$. La precipitación media anual, de $477 \mathrm{~mm}$, se concentra en los meses de diciembre y enero, existiendo, por otra parte una temporada seca con déficit en el balance hídrico entre los meses de mayo y septiembre, ambos inclusive.

\subsection{DATOS Y METODOLOGÍA}

Para el presente trabajo, un total de 21 puntos de control fueron distribuidos por el área de estudio (Figura 2), cada uno de los cuales fue georreferenciado en el sistema ETRS-89. Durante noviembre de 2014 se procedió a la adquisición de imágenes de las marismas de Isla Cristina, mediante la utilización de un UAV equipado con un sistema radar capaz de obtener y grabar los diferentes puntos del Paraje Natural (los datos tomados con el UAV se efectuaron durante la marea baja). Igualmente, y a la vez que las imágenes radar, fueron tomadas imágenes RGB (380-780 nm), que junto con las imágenes MAR procedentes del Pléiades (pancromáticas de resolución $0.5 \mathrm{~m}$ obtenidas de la plataforma AIRBUS DEFENSE \& SPACE, de las que se extrajeron datos necesario para el estudio de la topografía y la pendiente de las marismas de Isla Cristina), para el periodo comprendido entre enero de 2013 y noviembre de 2014, y obtenidas en diciembre de 2014 (se obtuvieron un total de tres imágenes MAR en cada uno de los meses del periodo citado, enero-2013 a noviembre-2014, con el propósito de disponer de suficientes datos a consecuencia de la variabilidad temporal y estacional existente en las imágenes de la zona de estudio), sirvieron para caracterizar adecuadamente el Paraje Natural Marismas de Isla Cristina.

Con el fin de obtener el volumen total de suelo erosionado en la zona de estudio, todas las imágenes adquiridas fueron ortorectificadas mediante sendos MDE de 25 (del año 1992-1999 del Instituto Geográfico Nacional (IGN), y de 3 m de precisión vertical) y 10 (del año 2001-2002 de la Junta de Andalucía, y de $3 \mathrm{~m}$ de precisión vertical; además del revisado con datos LIDAR a partir del vuelo fotogramétrico del 2001-2002 de la Junta de Andalucía, cuya exactitud en cota está entre 0.15 y 0.30 m) 
m de resolución, a excepción de las imágenes RGB captadas mediante el UAV, que fueron ortorectificadas en base al MDE, de $1.5 \mathrm{~cm} /$ pixel de resolución, calculado a partir de los datos conseguidos por su sensor radar (este MDE obtenido con el UAV se elaboró en la segunda quincena de diciembre de 2014). Todos y cada uno de los MDE's utilizados tuvieron un nivel de resolución favorable para obtener las diferentes cotas de las marismas de Isla Cristina, gracias a la ayuda de los puntos de control seleccionados, así como de cálculos basados en procesos iterativos (Matgen et al., 2007). Del mismo modo, y tanto para cada pixel como en cada MDE, se utilizó el tratamiento de datos basados en procesos iterativos, con el fin de obtener la profundidad media del agua en el Paraje Natural, lo que fue necesario para obtener el suelo erosionado en esta marisma.

Figura 2. Distribución de los puntos de control en el área de estudio.



De acuerdo con Juidias et al. (2013), una profunda revisión bibliográfica fue llevada a cabo con el objeto de determinar la posible existencia de un registro temporal de precipitación lo suficientemente amplio como para obtener unos resultados, discusión y conclusiones coherentes con el presente estudio. En este sentido, los datos de precipitación fueron analizados a partir de los suministrados por Climatedata.org (2015) para las localidades de La Redondela, Isla Cristina, Isla Canela y Ayamonte, necesarios para predecir la precipitación en las marismas de Isla Cristina desde 1982 hasta 2012 a partir de la correlación existente (Tabla 1) entre los datos climatológicos de las diferentes localidades.

Tabla 1. Correlaciones entre las precipitaciones de Ayamonte, Isla Canela, Isla Cristina y La Redondela para el periodo 1982-2012.

$\begin{array}{lcccc} & \text { Ayamonte } & \text { I. Canela } & \text { I. Cristina Redondela } \\ \text { Ayamonte } & 1 & & & \\ \text { I. Canela } & 0.9998683 & 1 & & \\ \text { I. Cristina } & 0.9993261 & 0.9996387 & 1 & \\ \text { Redondela } & 0.9988800 & 0.9992861 & 0.9998642 & 1\end{array}$

\section{RESULTADOS}

\subsection{CAMBIOS DE USO DE SUELO}

Extendidas por los términos municipales de Isla Cristina y Ayamonte, las marismas de Isla Cristina han sufrido una importante transformación debido al aumento de superficie dedicada a las actividades acuícolas. En base a la Consejería de Medio Ambiente (CMA) (2011), y considerando las áreas alteradas 
o construidas, entre 1956 y 2007 se puede apreciar un incremento significativo de las mismas a consecuencia de la expansión del tejido urbano en zonas costeras y, en relación al aumento del turismo, de la agricultura intensiva y de las áreas industrializadas.

La evolución seguida por los cultivos ha sido desigual. Mientras que las tierras arables han permanecido estables en superficie, la extensión de otros cultivos, caso de los forestales, ha disminuido drásticamente (60 \% entre 1956 y 2007). Por su parte, la superficie dedicada al regadío se ha visto favorecida por los avances tecnológicos, aumentado entre 1956 y 2007 espectacularmente.

En otro orden de temas, aunque ha habido un ligero incremento de superficie dedicada a la marisma entre 1956 y 2007, en 2007, y como consecuencia del aumento de las actividades acuícolas, el área total de la marisma era de un $9 \%$ menor en comparación con su superficie original.

\subsection{PREDICCIÓN DE LOS PROCESOS DE CAMBIO VOLUMÉTRICO}

Según Juidias et al. (2013), y tras analizar todos los datos disponibles, se detectó una progresiva disminución de la superficie de agua en las marismas de Isla Cristina, cuyas causas principales han sido, por una parte el incremento de la actividad humana alrededor del área de estudio, y por otra el descenso acumulado de precipitación, lo que indica que la zona se encuentra bajo la influencia de un periodo seco.

Posteriormente, y con la ayuda de Ilwis GIS, fue llevado a cabo un análisis conjunto entre los diferentes MDE's, y las características climatológicas de la zona, con el fin de obtener la predicción de volumen de inundación en función del MDE utilizado (Tabla 2).

Tabla 2. Predicción del volumen de inundación en base al MDE utilizado (“y” es el volumen obtenido en las marismas de Isla Cristina en $\mathrm{hm}^{3}$, y " $\mathrm{S}$ " es la superficie estimada que ocupa dicho volumen en " $\mathrm{km}^{2}$ ").

\begin{tabular}{|c|c|c|}
\hline MDE & Ecuación & Significancia \\
\hline \multicolumn{2}{|c|}{ MDE $20 \mathrm{my}=-4.134+0.789 \cdot \mathrm{S}$} & \multirow[t]{3}{*}{$\leq 0.001$} \\
\hline & $\mathrm{r}=0.976$ & \\
\hline & $\mathrm{R}^{2}=0.95$ & \\
\hline \multicolumn{2}{|c|}{$\mathrm{MDE} 10 \mathrm{my}=-3.981+0.714 \cdot \mathrm{S}$} & \multirow[t]{3}{*}{$\leq 0.001$} \\
\hline \multicolumn{2}{|r|}{$\mathrm{r}=0.978$} & \\
\hline & $\mathrm{R}^{2}=0.954$ & \\
\hline MDE & $y=-4.219+0.780 \cdot S$ & \multirow[t]{3}{*}{$\leq 0.001$} \\
\hline UAV & $\mathrm{r}=0.979$ & \\
\hline & $\mathrm{R}^{2}=0.957$ & \\
\hline
\end{tabular}

Después de efectuar la predicción volumétrica de las marismas de Isla Cristina, y en base a los datos de precipitación y a las características topográficas de la zona de estudio, se ha comprobado que su superficie total, 2498.04 hectáreas, se corresponde con un volumen de inundación de $18.11 \cdot 10^{6} \mathrm{~m}^{3}$.

En la Figura 3 se muestra el gráfico correspondiente a la estimación de superficie y su equivalencia en volumen de inundación. 
La profundidad estimada (Tabla 3) en cada uno de los puntos de control establecidos en campo, fue obtenida mediante procesos iterativos usando un total de 400 puntos seleccionados al azar con Ilwis GIS, cálculo necesario para poder identificar el suelo erosionado en estas marismas.

Igualmente, un análisis de varianza de un factor para muestras correlacionadas fue llevado a cabo para la variable profundidad estimada, y en función del MDE utilizado, cuyos resultados se muestran en la Tabla 4.

Además, y con el fin de revisar las diferencias entre MDE's, un estudio HSD de Tukey fue efectuado, observándose diferencias significativas ( $\mathrm{p} \leq 0.01)$ entre los MDE's de 20 m y de $10 \mathrm{~m}$, así como entre el de $10 \mathrm{~m}$ y el obtenido con UAV, resultado esperable habida cuenta de los datos utilizados. Sin embargo, la interacción entre los MDE's de 20 m y calculado con UAV no fue significativa, quizás debido a que el vuelo del UAV se realizó a tal altura (50 m sobre el suelo) que permitió al sensor radar capturar la totalidad de la densidad vegetal existente en la marisma, dándose como resultado una semejanza al azar con el MDE de $20 \mathrm{~m}$.

Figura 3. Superficie y volumen estimados.

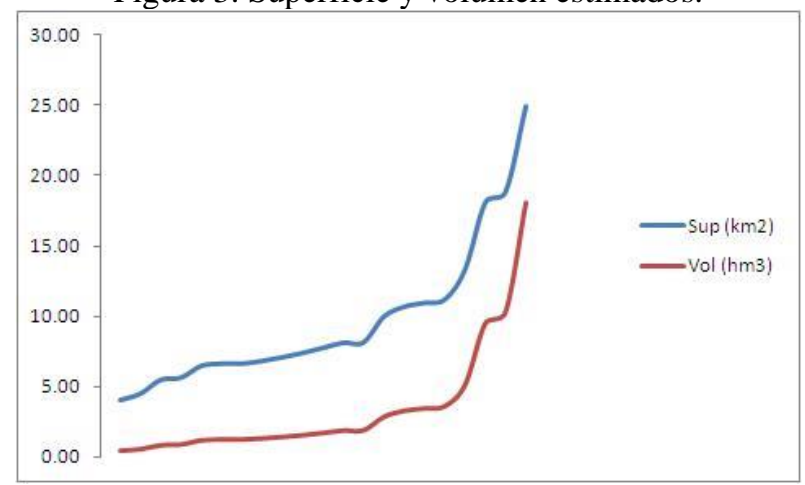

\subsection{PREDICCIÓN DE LA EROSIÓN EN LAS MARISMAS DE ISLA CRISTINA}

El transporte de sedimentos se obtuvo, a través de la evaluación de píxeles, entre cada uno de los MDE's utilizados (Figura 4). En dicha figura, se simula el transporte de sedimentos para el periodo comprendido entre 1982 y 2012 a partir de las características (precipitación y temperatura) del mismo y mediante la utilización del procedimiento patentado por Ramírez-Juidías et al. (2013).

Posteriormente, se aplicó una regresión linear múltiple a todos los datos obtenidos para poder predecir el volumen total de suelo erosionado entre 1982 y 2012 (Ecuación 4).

$$
\begin{gathered}
\mathrm{y}=0.032-0.133 \cdot S D-1.164 \cdot \mathrm{T} \\
\mathrm{r}=0.973 ; \mathrm{R}^{2}=0.941
\end{gathered}
$$


donde "y" es la predicción de volumen total de suelo erosionado en las marismas de Isla Cristina en $\mathrm{hm}^{3}$, "SD” es el área equivalente, en $\mathrm{km}^{2}$, en la que ha ocurrido el volumen de suelo erosionado, y en la que se ha producido un aumento o disminución en la cota " $T$ " contada a partir de la más baja obtenida por procesos iterativos entre MDE's, y validando la misma en base a la clasificación de las imágenes MAR realizada en las condiciones especificadas por Ramírez-Juidías et al. (2013).

Tabla 3. Profundidad estimada por punto de control en base al MDE utilizado.

\begin{tabular}{|c|c|c|c|}
\hline \multirow{2}{*}{$\begin{array}{l}\text { Punto de } \\
\text { Control n }\end{array}$} & \multicolumn{3}{|c|}{ Profundidad estimada $(\mathrm{m})$ para cada MDE } \\
\hline & MDE $20 \mathrm{~m}$ & MDE $10 \mathrm{~m}$ & MDE UAV \\
\hline 1 & 0.26 & 0.26 & 0.27 \\
\hline 2 & 0.29 & 0.28 & 0.30 \\
\hline 3 & 0.36 & 0.32 & 0.35 \\
\hline 4 & 0.37 & 0.36 & 0.38 \\
\hline 5 & 0.42 & 0.39 & 0.41 \\
\hline 6 & 0.43 & 0.43 & 0.43 \\
\hline 7 & 0.43 & 0.43 & 0.43 \\
\hline 8 & 0.44 & 0.44 & 0.44 \\
\hline 9 & 0.46 & 0.45 & 0.46 \\
\hline 10 & 0.48 & 0.47 & 0.48 \\
\hline 11 & 0.50 & 0.49 & 0.50 \\
\hline 12 & 0.53 & 0.52 & 0.52 \\
\hline 13 & 0.53 & 0.53 & 0.57 \\
\hline 14 & 0.65 & 0.59 & 0.64 \\
\hline 15 & 0.70 & 0.67 & 0.69 \\
\hline 16 & 0.71 & 0.71 & 0.71 \\
\hline 17 & 0.73 & 0.72 & 0.77 \\
\hline 18 & 0.87 & 0.80 & 0.92 \\
\hline 19 & 1.18 & 1.03 & 1.14 \\
\hline 20 & 1.23 & 1.21 & 1.35 \\
\hline 21 & 1.63 & 1.43 & 1.57 \\
\hline
\end{tabular}

Tabla 4. Resumen del análisis de varianza (ANOVA) para la variable profundidad estimada $(\mathrm{SS}=$ suma de cuadrados; $\mathrm{df}=$ grados de libertad; $\mathrm{MS}=$ media cuadrática; $\mathrm{F}=$ valor del estadístico de prueba; $\mathrm{P}=$ significancia).

\begin{tabular}{|c|c|c|c|c|c|}
\hline & SS & $\mathrm{df}$ & MS & $\mathrm{F}$ & $\mathrm{P}$ \\
\hline $\begin{array}{l}\text { Tratamiento } \\
\text { (entre grupos) }\end{array}$ & 0.017552 & 2 & 0.008776 & 8.78 & 0069 \\
\hline Error & 0.0413 & 40 & 0.001 & - & - \\
\hline $\begin{array}{l}\text { Bloques } \\
\text { (MDE's) }\end{array}$ & 6.6067 & 20 & - & - & - \\
\hline Total & 6.6656 & 62 & - & - & - \\
\hline
\end{tabular}

\section{DISCUSIÓN}

En función a los procesos de erosión dinámica que se producen en el Paraje Natural Marismas de Isla Cristina, el área de estudio puede ser dividida en dos zonas claramente diferenciadas. La zona Este, situada a la derecha del eje del río Carreras, presenta unos niveles medios de erosión total más bien bajos, de $0.02 \mathrm{~m}$, probablemente debido a la baja presión industrial existente alrededor de esta zona. Sin embargo, la parte Oeste (izquierda del eje del río Carreras) posee unos niveles medios de erosión total a 
tener en cuenta, $0.13 \mathrm{~m}$, en gran parte a consecuencia del efecto de las mareas, aunque no hay que olvidar los altos niveles de presión antrópica que se dan en sus inmediaciones.

Figura 4. Variación de la profundidad en las marismas de Isla Cristina por transporte de sedimentos entre 1982 y 2012.

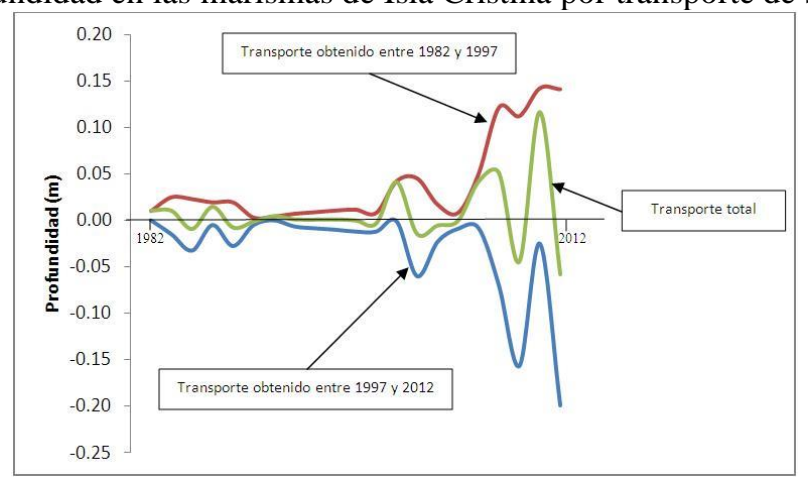

Tal y como se ha podido comprobar después de realizar la simulación de transporte sedimentario, el MDE obtenido con UAV, y tras efectuar la clasificación oportuna de las imágenes MAR, tuvo como resultado una mejor predicción de volúmenes, siendo uno de las principales causas la preservación ecológica de la zona.

Con respecto a los CUS, es importante decir que están relacionados con la pérdida de humedales debido al, lento pero progresivo, incremento del nivel negativo de suelo erosionado (deposición sedimentaria).

En conclusión, es muy importante usar conjuntamente UAV-MAR, para predecir la erosión de espacios marismeños. 


\section{BIBLIOGRAFÍA}

Climate-data.org. 2015. Datos climáticos mundiales. En http://es.climate-data.org/, acceso: 03/01/2015. Consejería de Medio Ambiente. 2011. Medio siglo de cambios en la evolución de usos del suelo en Andalucía 1956-2007. Editorial Junta de Andalucía.

Juidias, E.R., Segovia, M.J. \& Luna, A.M. 2013. New method to predict the volumetric changes in the Odiel marshes (Huelva, Spain). Lecture Notes in Engineering and Computer Science: Proceeding of the Word Congress on Engineering, London, 1335-1339.

Matgen, P., Schumann, G., Henry, J.B., Hoffmann, L. \& Pfister, L. 2007. Integration of SAR-Derivated River Inundations Areas, High-Precision Topographic Data and a River Flow Model Toward Near RealTime Flood Management. International Journal of Applied Earth Observation and Geoinformation, 9; 247-263.

Ojeda-Zújar, J., Márquez-Pérez, J. \& Gómez, A. 2006. Restitución analítica, stereo-correlación y lídar para la generación de modelos digitales de terreno en marismas mareales. En Camacho, M.T. y otros (Eds.): "El acceso a la información especial y nuevas tecnologías geográficas". Editorial de la Universidad de Granada, 1121-1134.

Ramírez-Juidías, E., Pozo-Morales, L. \& Galán-Ortiz, L. 2013. Procedimiento para la Obtención de una Imagen Teledetectada a Partir de Fotografía. 14/06/2013. Universidad de Sevilla, España, Patente $\mathrm{n}^{\circ}$ P201300573 (con extensión a Patente Internacional nº W2014000097).

Ramírez-Juidías, E., Tejero-Manzanares, J., Moreno-Fresno, J.J., Justicia-Segovia, M., Madueño-Luna, A. \& López-Lineros, M. 2014. Land use changes and volumetric processes in the Tinto salt-marshes. In Book Abstracts 3rd International Conference on Challenges in Environmental Science and Computer Engineering, 5-5.

REDIAM. 2008. Compendio de cartografía y estadísticas ambientales de Andalucía. $2^{\text {a }}$ Edición. Junta de Andalucía, DVD.

Soto, M-V., Märker, M., Paz Castro, C. \& Rodolfi, G. 2015. Análisis Integrado de las Condiciones de Amenaza Natural en el Medio Ambiente Costero Semiárido de Chile. La Serena, Coquimbo. Boletín de la Asociación de Geógrafos Españoles, 67; 213-231. 